\section{EMBRYARIDDLE}

Aeronautical University

SCHOLARLY COMMONS
Journal of Aviation/Aerospace

Education \& Research

Volume 18

Number 2 JAAER Winter 2009

Article 6

Winter 2009

\title{
Multi-Cultural Factors in the Crew Resource Management Environment: Promoting Aviation Safety for Airline Operations
}

Donald S. Metscher

metscdb4@erau.edu

Marvin Smith

smithm@erau.edu

Abdullah Alghamdi

Follow this and additional works at: https://commons.erau.edu/jaaer

\section{Scholarly Commons Citation}

Metscher, D. S., Smith, M., \& Alghamdi, A. (2009). Multi-Cultural Factors in the Crew Resource Management Environment: Promoting Aviation Safety for Airline Operations. Journal of Aviation/ Aerospace Education \& Research, 18(2). https://doi.org/10.15394/jaaer.2009.1423

This Article is brought to you for free and open access by the Journals at Scholarly Commons. It has been accepted for inclusion in Journal of Aviation/Aerospace Education \& Research by an authorized administrator of Scholarly Commons. For more information, please contact commons@erau.edu. 


\title{
MULTI-CULTURAL FACTORS IN THE CREW RESOURCE MANAGEMENT ENVIRONMENT: PROMOTING AVIATION SAFETY FOR AIRLINE OPERATIONS
}

\author{
Donald S. Metscher, Marvin Smith, and Abdullah Alghamdi
}

\begin{abstract}
There are many reasons why Multi-cultural flight crews fail to work together effectively. This research provides a review of the history of Crew Resource Management (CRM), the CRM training classes, and the communication barriers among the flight crews. The national, organizational, and professional cultures of crew members influence flight safety. While the primary focus is on Saudi Arabian Airline, the findings can be generalized to any multicultural airline. CRM training has been shown to be efficient for both pilots and flight attendants when viewed separately, especially those flying in foreign countries. The authors address accidents which were caused as a result of the lack of communication between pilots and flight attendants. A survey was conducted of 30 pilots and 30 flight attendants employed by Saudi Arabian Airlines. The results indicated the population was aware of the importance of mixed cultural differences as useful aspects of training in areas of safety and the cooperation of crew members. Furthermore, it was revealed that good communication has significant effects on teamwork effectiveness and safety. The authors recommend that the airline should establish a joint annual CRM training class for both groups.
\end{abstract}

\section{Introduction}

Error is a normal event in the human condition. The Roman philosopher Cicero (Circa 50 A.D.) linked error to the basis of human behavior when he said, "To err is human." Although common, errors in aviation have been minimized over the years. This was a direct result of better technologies and the implementation of strict regulations and rigid procedures that govern our modes of operation.

\section{Background and Significance}

For many years, culture has been a safety related issue in the aviation community. Globalization of the airline industry is now a reality and is expected to continue. As airlines of different nations continue to combine operations and increase their international destinations, cultural issues will gain prominence. These new global air carriers will most likely develop a cultural mixture of cabin attendants that match those of the expected passenger load. Aircraft in commercial airlines are separated into two sociological and geographical environments, the cockpit and the cabin. Each area has different responsibilities which can be viewed as two separate cultures in the aircraft (Helmreich, Merritt, \& Wilhelm, 1999). Those two cultures are administratively organized into separate departments. The pilots are under flight operations where safety is stressed. The cabin crews are typically part of the marketing departments in many airlines where passenger service is emphasized.

Aircraft manufacturers are now designing 800 plus passenger aircraft. An increasing number of international airlines employ cockpit and cabin crews recruited from different countries and distinct cultures. In those airlines, the need for inter-cultural mixed Crew Resource Management (CRM) training arises. Furthermore, in view of the increasing use of multi-national crews by major international airlines, the need for universal inter-cultural training programs is also increasing.

Airline industry accident analysis shows that cabin safety and effectiveness is directly related to the level of flight deck and cabin crew integration. Globalization of the aviation industry should consider the effects of multi-culture when discussing aviation safety and effectiveness. Saudi Airlines, for example, since its foundation in 1945, has been a multi-cultural airline. The airline's employees come from over 35 different nationalities on the flight deck and $\mathbf{5 0}$ different nationalities in the cabin. The addition of mixed 
CRM training to this foundation will feature human factors skill training that breathes additional life into how all the crew functions in the aircraft by increasing the effectiveness of how well crew members work together.

Culture is a factor of how a person perceives the world. It is affected by such things as language, education, religion, and customs. There are both positive and negative effects. The overall advantages due to culturally mixed crews are that individual crew members can provide different interpretations of the same information and different approaches towards problem solving (Helmreich, Klinect, \& Wilhelm, 1999). Conversely, when these cultural differences are not channeled properly, misinterpretation of information can cause misunderstandings that will reduce crew effectiveness or lead to an accident. Each airline must analyze its own cultural effects when it considers its options on flight crew integration. Most airlines' primary method for reducing any negative multi-cultural effects and building on the positive effects to increase cabin and cockpit safety is through a high level of training and standardization (Merritt \& Helmreich, 1995). Since people of different cultures may have varying interpretations of the same situation, a high level of standardized training will refocus cultural variations so that crew members view a given situation with similar levels of understanding; such training is called mixed CRM.

There are two critical safety obligations of the flight attendant. The first is to prevent accidents, primarily by means of the conveyance of information regarding hazardous conditions to the flight deck. If the accident cannot be prevented, the second obligation is to maximize its survivability. Both roles require effective communication between the two work areas. Standardization of communication is also a vital factor. Flight crews use standard words or phrases for specific situations to prevent cultural misunderstandings. The effect of non-standard words or phrases among multi-cultural crewmembers is similar in effect to the use of slang words among crew members in those countries where English is the primary language (Merritt \& Helmreich, 1995).

When CRM was introduced, it began a process of humanizing the duties of the flight crew. Today, CRM is too narrow in scope, as accidents still occur in which the lack of cabin and flight deck crew interaction is a major cause. On the other hand, emergencies have occurred during which the effective interaction of CRM trained cabin and flight deck crews either prevented an accident or minimized the effects of an accident (Barnes, Orlady, \& Orlady, 1996).

Mixed CRM training increases the effectiveness of how the cabin and flight deck crew operate as a single flight crew by dealing primarily with human factors as opposed to classical training methods. What works in an organization with one culture may not work in the same organization with many different cultures. This is primarily because it opens crew members to the concepts of working together by focusing on what, not who, is responsible. Mixed CRM emphasizes the need to respect each others' different backgrounds and beliefs while drawing on those differences to arrive at the best possible solutions. It will help all crews to understand how multi-cultures view the same situation and communicate with each other; adjusting to each others' styles. By attending mixed CRM courses for multi-cultural airlines, the crew will learn and practice human factor skills during the course that will have value during actual flight operations (Orlady \& Orlady, 1999; Lusher, Leary, \& Frakers, 1995).

\section{Problem Statement}

Today, most foreign airlines depend heavily on the effectiveness of their multi-national crew and the crosscultural CRM instruction they provide to their pilots and flight attendants. However, the lack of standardization and the restrictions of personnel receiving the training jeopardize the program's success in achieving its safety objectives. The purpose of this research was to identify the significance of implementing a mixed CRM training program for both cockpit crew and flight attendants from different cultural, geographical, and vernacular backgrounds.

Review of the Literature

Culture can be defined as the values and practices that a group shares with others that help define them as a group, especially in relation to other groups. Culture also influences the values, the beliefs and the behaviors that the people share with other members of the group. It serves to bind people together as members of a group and to provide signs and signals as to how to behave in normal and emergency situations (Merritt \& Helmreich, 1995).

History of Crew Resource Management

The errors directly rooted from human interaction with technology are limited. In fact, technology has achieved high standards of reliability and efficiency in most aspects of its functions. On the other hand, the fact remains that the interaction of humans with technology remains the most common source of errors.

Crew Resource Management (CRM) is perhaps the most common human-related dilemma of flight operations in an airline environment. In 1984, Dr. John Lauber, a member of the National Transportation Safety Board (NTSB), defined CRM as "Using all available resources Information, Equipment, and People to achieve safe and 
efficient flight operations" (Lauber, 1984, p. 20). The Federal Aviation Administration (FAA) has defined CRM as the utilization of all available human, informational, and equipment resources toward a safe and efficient flight (FAA, 2001).

In 1951, a U.S. Air Force Inspector General (IG) report analyzed data for a study of major accidents which occurred between 1948 and 1951 (Kern, 2001). The study's results showed that the majority of aircraft accidents were due to human shortcomings such as personnel errors, poor organization, and poor teamwork. The IG recommended teamwork training programs as essential to reducing the accident rate.

Tragically, the crash of a United Airlines DC-8 in Portland, Oregon in December 1978 brought the attention of the aviation community to problems related to human factors. The accident started when the pilot in command's attention was diverted from flying the aircraft to a supposed landing gear problem. The landing gear subsequently proved to be down and locked. The aircrew allowed the aircraft to completely run out of fuel while circling near the airport on a clear night. The flight engineer had advised the captain numerous times that they were running out of fuel (NTSB, 1979).

History demonstrates that human factors are the leading cause of developing a CRM program. Over the last 90 years, human factors analysis has gradually evolved and is now at the forefront of aviation training and research. Training in this area has become the focal point for addressing multiple concerns associated with aircrew teamwork performance and pilot error.

In 1979, The National Aeronautics and Space Administration (NASA) sponsored a workshop in resource management for the flight deck. This meeting was the result of NASA research into air transport accidents. At this meeting, CRM was officially named Cockpit Resource Management, a formal training program to concentrate on the human factors in aviation. It was applied to the process of training crews to reduce "pilot error" by understanding and making better use of the human resources on the flight deck (Cooper, White, \& Lauber, 1980).

Airlines noticed that even though pilots were technically proficient, their people skills were deficient. In other words, the captain may fly a perfect instrument approach, but cannot work in an interactive environment to effectively accomplish a task (Kern, 2001). In this view of the pilot as the most important central figure, CRM was originally designed for the pilot, hence Cockpit Resource Management. This name has been under attack from the beginning. Flight attendants for example, took offense because it excluded them even though they are part of the crew and perform duties in the aircraft like the pilots, except they are on the other side of the cockpit door.

Pilots and flight attendants are not only on different sides of the door, they are traditionally different genders as well. Pilots, mostly males, are individuals and need to be taught how to act in teams. On the other hand, the flight attendant is a mostly female dominated profession. Even though there has been an increased percentage of gender balancing over the last few decades for both groups, there is still a lot of conflict between them (Chute \& Weiner, 1995; Chute, 2002). According to Chute (2002), gender, stereotypes and national culture are among the psychosocial issues involved in the information transfer model that can impact cabin communication and coordination.

In 1993, NASA arranged another meeting (Cooper et al., 1980) where they realized that the need for CRM would disappear when it becomes part of the fabric of flight training and flight operation. The training eventually branched out to include not only the pilots, but also flight attendants, mechanics, dispatchers and anyone involved in the safe completion of a flight.

Therefore, a new generation of CRM courses emerged and the name was changed from Cockpit Resource Management to Crew Resource Management to include all members of the flight team, both inside and outside the aircraft. The major principle of CRM in the flight operations is to place shared responsibility for safety on all flight crew members.

There are some examples of communications breakdown between these two groups. In 1989, 24 passengers and crewmembers, including both pilots, were killed in an Air Ontario crash on take off from Dryden, Ontario because of an accumulation of snow and ice on the wings of the aircraft. Several passengers informed the flight attendants about the ice while the aircraft was taxiing. Unfortunately the flight attendants did not inform the pilot about the passenger's concerns with the icing conditions because they believed that the pilots did not welcome operations information from cabin crewmembers (Baron, 2004; Helmreich, 1992).

Another example of communication breakdown occured when a pilot of a three man flight deck had an abnormal situation due to one of the hydraulic systems failing after takeoff. When the crew discovered the problem, they implemented the CRM in the cockpit only by letting the first officer fly the aircraft while the captain and the flight engineer did the checklist. The captain decided to 
return to the departure airport for landing without informing the flight attendants about the situation and kept them isolated until after landing (M. Smadi, personal communication, January 17,2005$)$. These examples tell us of some of the problems the airline industry confronts and these problems are even more severe in foreign airlines, where flight crew members are frequently from different cultures and speak different languages.

Culture plays a strong role in all airlines and airline managers must have a full understanding of cultural influences on their operations if they are to be successful in safety. Culture has strong influences on every single department in domestic and foreign airlines, but the flight crew faces cultural challenges more than other departments because of their close working conditions and the critical safety issues.

\section{A Cultural Dilemma}

Within the culture of the international aviation community, diversity is hidden by a high level of information exchange, advanced technology, and the "language of aviation" (Merritt \& Helmreich, 1995). The technological advances in aviation have been increasing for the past decade and have helped reduce individual workload and have decreased the probability of human error. Improved technology's effect on aviation safety has become more significant as most major airlines in the world operate new models of aircraft, such as the Boeing 777 and the Airbus 340. People must be receptive to change. The increased use of technology is changing the way all crewmembers work. New skills are needed to replace the old ones that served so well in the past.

Human factors are concerned with solving practical problems in the workplace. It is all about relationships of individuals with each other and with situations. It includes such things as how people communicate and behave during individual and group situations. Most communication involves speaking, reading, writing, listening, and nonverbal signals (Sexton \& Helmreich, 2000). Recurrent and initial training in the airline has said little about communication between cockpit and cabin, except in extreme cases such as hijacking or evacuation. The quality and effectiveness of communication is largely determined by how well individuals understand what is being said. Therefore, one task of human factor training is to increase communication skills and reduce communication errors (Wiener, 1996).

Each flight crew is made up of a flight deck and cabin crew. Both need to work together; this is especially important during abnormal or emergency situations. As previously mentioned, there are differences between the flight deck and the cabin crew's duties. One major difference involves the priorities of the two crews. The flight deck crew is focused on the technical side of controlling the aircraft and operating the systems. The cabin crew deals less with technical things and concentrates more on people. Their activities require a lot of communication and coordination (Phillips, 1994). However, problems can occur during time-critical situations. Then the question arises whether both crews really understand the overall duties, abilities, or concerns of the "other" crew? Have they had the opportunity to train together in high workload or time-critical situations? Is there a reason to train together in these situations or should they assume that everything will work out ok?

In examining the comments of crewmembers after an in-flight emergency, especially when close coordination of both crews was required, the need for human factors training is indicated. Look at a typical Boeing $747 \mathrm{crew}$ of approximately $20 \mathrm{crew}$ members. In some airlines, these 20 crew members come from more than one country, and each will differ in values, expectations, beliefs, behaviors, attitudes, backgrounds, culture, national identity, religions, etc. Even among people from the same country there are tribal or regional differences. It is not unusual to find cultural differences in different areas of the same city of a single cultural country. Some days the only common ground that the crew members may have is the job at hand.

The highest levels of safety are reached when all crewmembers contribute their best efforts toward a common goal. Each member of the crew has an assigned role in the aircraft. This role must be clearly defined and communicated, so that each member clearly knows what is expected of him or her and what to expect from others. The cockpit crew, as well as the cabin crew, needs to take specific initiatives towards building a team that functions effectively. The culture of the cockpit crew is very different from that of the cabin crew because each has different priorities and value systems. Flight deck crews focus mainly on flying the aircraft and operating systems. Their culture is considered to be of a technical nature. The cabin crews focus mainly on cabin safety and passenger

service. Their culture is oriented towards people and involves a lot of communication and coordination (Baron, 2004).

The different focus of each crew tends to develop a feeling of separation between them. This feeling usually begins before the crews enter the aircraft. In many airlines, the scheduling of crews is such that often the cockpit and 
cabin crews may see each other only briefly before a flight because of different reporting times and the need for the flight deck crew to initially attend the dispatch briefing. The crews may not see each other until they are at the aircraft. When the flight crew enters the aircraft, cabin attendants are usually busy with their individual pre-flight. Since both crews are preoccupied with their own priorities, the captain normally briefs only the cabin supervisor. This sets the stage for poor communications. If the captain does not brief the remaining cabin attendants, they may not know what is expected of them and they can only rely on experience. The consequences of this may become apparent in emergency situations when crew members must work together as a team (Wiener, 1996). The point is that cockpit crew and cabin attendants really need to know the basic ground rules for crew interaction. Unless ground rules are established, through mixed CRM for example, barriers are created.

Mixed CRM training between cockpit crew and cabin crew may reduce the negative multi-cultural effects when the team focuses on what is right and not on who is right. If mixed CRM training can get the team to focus on the task, and work on the best way to accomplish it, many of the cultural differences will automatically be neutralized.

Culture plays significant roles in the airline industry, especially in the flight portion. In aviation, the three cultures-National, Professional, and Organizational, can have both a positive and a negative impact on the probability of safe flight. The responsibility of organizations is to minimize the negative components of each type of culture while emphasizing the positive (Helmreich, n.d.). Pilots and flight attendants are dealing with three cultures: Their individual national cultures, professional pilot culture and organizational culture. These three cultures can have both positive and negative impacts on the probability of safe flight.

National culture begins to influence an individual as soon as her/his senses become aware of the surrounding world. This process continues throughout an individual's life. It has a strong effect on the operational environment. National culture represents the shared components of national heritage (Helmreich, Wilhelm, Klinect, \& Merritt, 2001; JAR TEL, 1998). These include behavioral norms, attitudes, and values. In the aviation industry some aspects of national culture have been identified as individualism, collectivism, uncertainty, and power distance. While collectivists are more accustomed to their primary groups, the individualists focus on the self and personal benefits.

Professional culture influences through feelings of responsibility and dedication to executing one's job as effectively as possible. Professional pilot culture reflects attitudes and values associated with the respective profession (Helmreich et al., 2001; JAR TEL, 1998). The aviation professional culture among pilots is very strong. Pilots like their job, pilots take great pride in their profession and have a strong motivation to perform to the best of their ability.

Organizational culture involves how the organization influences people in that particular organization or company. Much of this influence comes through formal and informal policies and procedures. It is fairly consistent over long periods of time. Organizational culture provides the shell within which national and professional cultures operate and is a major determinant of behavior (Helmerich et al., 2001; JAR TEL, 1998). Organizations are becoming multicultural. Individuals from different nations are working together in the aviation industry, resulting in language and communication barriers among pilots and flight attendants.

All these cultures surround the individuals and their organizations. Each of them have strengths and weaknesses. The strengths enhance safety and the weaknesses diminish it. There are many problems when two seemingly separate crews operate an airliner. The primary problem with pilots and flight attendants is a lack of effective communications. The root of this problem is the disparate job functions and responsibilities of both groups. Inside the aircraft, the pilots are in the cockpit and the flight attendants are in the cabin, both are separated by the cockpit door, so each group considers itself in its own territory. The communication between the two groups is conducted through an impersonal interphone (Nilsson \& Roberg, 2003).

The only times that these two groups would interface with each other physically is in the briefing room before the flight, in an emergency situation, or when pilots need anything from the flight attendants, such as meals. In addition, the communication barrier was further widened by the cockpit door-strengthening requirement after the events of September 11, 2001 (Chute, 2002). Another barrier to effective communication between the two groups is the sterile cockpit rule that was promulgated by the 14 CFR Part 121 in 1981 (FAA, 2005). This rule was implemented to eliminate non-essential communication between the pilots themselves, and between them and the cabin crew during critical phases of flight such as taxi, takeoff, and approach. This rule compounded the ambiguity for the flight attendants of what should be communicated to the cockpit, and the consequences of whether he or she is wrong, even if he or she feels that the information is critical. 
In a study of personality differences of pilots and flight attendants, America West CRM facilitators found "pilots to be task-oriented, preferring a cognitive style of problem solving based on logic and systems-oriented reasoning. Flight attendants, however, prefer an affective/cognitive style and orientation to decision making" (Chute \& Weiner, 1995, p. 260). Pilots have approached their job as a career but many flight attendants frequently view their jobs as a temporary one. The pilot is in charge of the operation of the aircraft and leaves the responsibility of the cabin to the flight attendants. Until a problem is brought to the pilot's attention, it can be seen that generally the crews function together harmoniously (Chute \& Wiener, 1995).

Chute and Wiener (1995) further note that flight crew communication is not always optimal. The conflict between these two groups has roots in all cultures and countries. Research shows that the division in these groups may be attributable to historical, environmental, organizational, psychosocial, and regulatory factors (Chute $\&$ Wiener, 1996). "The two crews are drawn from two disparate cultures, one dedicated to and highly proficient in technical matters, particularly the operation of complex machinery, the other well-versed in sociability and public service" (Chute \& Wiener, 1996, p. 213). The two different crews are usually administratively organized into separate departments. The pilots are often under the flight operations department where safety is stressed and the cabin crews are typically part of the marketing department where the emphasis is on service (Chute \& Wiener, 1995). This separation can lead to "inconsistencies such as conflicting information in their respective manuals and procedures...that contribute to misunderstandings and problems in coordination and communication on the part of airline crews in the performance of their duties" (Chute \& Weiner, 1995, p. 258).

Amongst other things, CRM teaches pilots and flight attendants how to examine communication skills, interpersonal duties such as leadership and coordination, effective team formation, problem-solving, decision-making and maintaining situational awareness. The airlines tried to familiarize the cockpit and cabin crew with the above factors to encourage them to perform effectively as a team. Despite this, there has been an unrelenting division of these two groups in times of routine operation and emergencies (Chute, 2002).

Many airlines view the CRM program very seriously; others do just the minimum. Unfortunately, in some cases, CRM failed to recognize the variability in programs. Some were carefully designed and reflective of their organization's culture, others were mere exercises in compliance with requirements. Depending on the airline, the CRM course has been taught differently (Chute \& Wiener, 1996). The initial course was about raising awareness of the problem of human factors and encouraging attitude change. These were followed by annual recurrent courses, which provided an opportunity to address specific issues that may have arisen in the preceding year as well as reinforcing the message of the initial course.

Each airline has a common objective-to fly safely and efficiently while making a profit for the parent organization. When an airline has a common objective, it works well together when things are going as they should. The CRM program tries to achieve these objectives. It explicitly focuses on error and its management. The CRM program also tries to build a trust between the pilots and the flight attendants.

Today, CRM is required training for all airline operations, as per Advisory Circular 120-51D(FAA, 2001). Some airlines are using an already established CRM program from another organization. It seems that the off the shelf solution CRM programs from other organizations do not produce positive effects if they are not calibrated according to the cultural and organizational cell of the borrowing organization. The following example shows the different reactions to CRM among different cultures. A Japanese airline adopted the U.S. style CRM course and questioned whether this type of western-style training program could be adapted to a Japanese way of thinking, especially since the program deals with human behavior problems. They observed that U.S. pilots are task oriented and are aware of themselves as individual rather than as part of the group. With the U.S. pilots, an individual independent self is encouraged. Japanese pilots, on the other hand, are more group oriented, modest and are likely to accept the opinion of others to preserve harmony within the group and to allow their own ideas to be dropped in the face of opposition (Helmreich, 1999).

The same problem has been raised among the flight attendants, and between the flight attendants and the pilots. Each of the groups has different training throughout their careers and in many multi-cultural airlines the two groups have separate CRM training, which has been viewed as efficacious for both groups. Pilot CRM skills provide countermeasures against risk and error in the form of trust and error avoidance, detection, and management, but the flight attendants' CRM provides more safety and teamwork training. 
In actual flight, the pilots and flight attendants operate together and there are physical and cognitive factors that influence both groups to work less efficiently, especially in a critical cohesive environment such as an emergency. In the emergency situation, these two groups react differently, because of different CRM training.

The CRM course concept is to maintain teamwork. Teamwork can be achieved when crews consider each other's job tasks, communicate with others in a timely manner, keep each other informed, and support others by keeping each other up-to-date.

In many airlines of the world the pilots and flight attendants come from different countries, each with their own language and attitude, yet in their profession, they must be able to work closely together and function as a team. Throughout the Middle East, airlines often have multicultural crew. However, in the Persian Gulf area specifically, all airlines are multi-cultural. Saudi Arabia is no exception; its one major airline, Saudi Arabian Airline, employs workers from numerous other countries.

\section{Resarch Mehtodology Participants}

Saudi Arabian Airline's pilots and flight attendants were the primary sources of the participants in this survey because the airline crew is multi-cultural. The participants were selected by means of random sampling from the population of current pilots and flight attendants of Saudi Arabian Airline's home base, Jeddah, Saudi Arabia. This produced a closer view of what actually happens between the flight attendants and the pilots.

A simple random sample of participants was selected for the survey. The purpose of the survey was to gather data on the participants' perceptions and attitudes regarding the mixed Crew Resource Management (CRM) training in the airline. The result reflected the individual viewpoint of a participant or observer.

\section{Instrument}

Saudi Arabian Airline's pilots and the flight attendants were surveyed to evaluate the problem statement using a data collection instrument. The study consisted of two sections; the first section was demographic, to identify the subject's general information such as age, field specialization, and work experience. The second section included 15 questions to obtain specific information regarding personal knowledge about CRM, cultural barriers between both groups, and a personal opinion about mixed CRM training to serve as a measuring instrument.

To avoid any bias and to get permission and assistance to administer the surveys, the survey instrument was provided to the general managers of the flight operation and flight training departments for both pilots and flight attendants. Each of these managers distributed the survey questionnaires to approximately 150 pilots and flight attendants in their mailboxes in the Saudi Arabian Airline flight operation, out of the total of nearly 3000 flight crew. Communications with the researcher were written and anonymous. No name or identification numbers were collected to ensure subject anonymity and confidentiality.

A cover letter was attached to each questionnaire to clarify the purpose of the research study. An envelope with a return address was provided with each questionnaire. A copy of the questionnaire accompanied by its cover letter is contained in the Appendix A section of this project.

\section{Design}

The survey questionnaire was exclusively designed for the purpose of this study and a descriptive research method was used. The primary data, the completed questionnaire collected from the participants, were analyzed and evaluated as the data was returned, using an appropriate statistical technique such as the Statistical Package for Social Sciences (SPSS) and Microsoft Excel 2003. The results were examined and a detailed description of the groups was provided.

\section{Results}

The research questionnaire developed for this study gathered information on the respondent's opinions regarding whether mixed Crew Resource Management (CRM) will promote aviation safety for airline operations with multicultural flight crewmembers. Of the 150 surveys, questionnaires randomly distributed to both cockpit and cabin crew personnel, a total of 30 surveys were returned from each group, and were separately analyzed.

Demographic Data

This section identifies the subject's age, field specialization, work experience, and if the subjects ever attended mixed CRM training.

Table 1 shows both Cockpit and Cabin crews' ages. It shows 6 pilots (20\%) of the cockpit crews' ages were between 20-30 years, 9 pilots (30\%) were between 31-40 years, 12 pilots $(40 \%)$ were between $41-50$ years, and 3 pilots $(10 \%)$ were over 50 years. In addition, it shows the cabin crew's ages in which $9(30 \%)$ of the cabin crews were between 20-30 years. In addition, 9 cabin crew (30\%) between the ages of 31 and 40 years, $6(20 \%)$ were between 41-50 years, and $6(20 \%)$ were over 50 years. 
Table 1

Respondents Age

\begin{tabular}{lccc}
\hline & & $(\mathrm{N})$ & $(\%)$ \\
\hline 20-30 years & Cockpit crews & & \\
31-40 years & & 6 & 20.0 \\
41-50 years & 9 & 30.0 \\
Over 50 years & & 3 & 40.0 \\
Total & & 30 & 10.0 \\
\hline & & 100.0 \\
20-30 years & Cabin crews & 9 & \\
31-40 years & & 9 & 30.0 \\
$41-50$ years & & 6 & 30.0 \\
Over 50 years & 30 & 20.0 \\
Total & & 20.0 \\
\hline
\end{tabular}

Table 2 shows the field specialization of both groups. The first group consisted of 30 cockpit crew members (50\%), while the second group represented 30 cabin crew members (50\%).

Table 2

Field Specialization

\begin{tabular}{lcc}
\hline & $(\mathrm{N})$ & $(\%)$ \\
\hline Cockpit crews & 30 & 50.0 \\
Cabin crews & 30 & 50.0 \\
Total & 60 & 100.0 \\
\hline
\end{tabular}


Table 3 shows the cockpit and cabin crews' years of experience in the aviation industry. The years of work experience of the cockpit and cabin crews range from 1 year to over 31 years. The results show that there are 4 pilots (13\%) who had fewer than 10 years of work experience, 15 pilots (50\%) had between 11 and 20 years' experience, 7 pilots (24\%) had between 21 and 30 years of experience, and 4 pilots (13\%) had over 31 years of pilot experience. Table 3 also shows 8 cabin crewmember (27\%) with experience of less than 10 years, 8 cabin crew (27\%) with work experience between 11 and 20 years, 6 cabin crew (19\%) between 21 to 30 years of experience, and $8(27 \%)$ of the cabin crews worked over 31 years in the field of aviation.

Table 3

Work Experience

\begin{tabular}{lccc}
\hline & & $(\mathrm{N})$ & $(\%)$ \\
\hline & Cockpit crews & 4 & \\
1-10 years & & 15 & 13.0 \\
$11-20$ years & & 7 & 50.0 \\
21-30 years & & 4 & 24.0 \\
Over 31 years & & 30 & 13.0 \\
Total & & 8 & 100.0 \\
\hline & & 8 & 27.0 \\
1-10 years & Cabin crews & 6 & 27.0 \\
$11-20$ years & & 8 & 19.0 \\
21-30 years & & 30 & 27.0 \\
Over 31 years & & & 100.0 \\
Total & & & \\
\hline
\end{tabular}

In Table 4, the results measured whether either of the crews ever attended mixed CRM training or any training to help in how to communicate and cooperate or not. Of the 30 pilots, 23 pilots (77\%) had this type of training while 7 of the pilots (23\%) did not have any training in this field. In addition it shows 14 cabin crewmembers (47\%) acknowledged having this type of training. Conversely, 16 cabin crewmembers (53\%) responded that they had never attended this type of training.

Table 4

Training

\begin{tabular}{llcc}
\hline & & $(\mathrm{N})$ & $(\%)$ \\
\hline & Cockpit crews & & \\
Yes & & 23 & 77.0 \\
No & 7 & 23.0 \\
Total & 30 & 100.0 \\
\hline & & & \\
Yes & Cabin crews & 14 & 47.0 \\
No & & 16 & 53.0 \\
Total & & 30 & 100.0 \\
\hline
\end{tabular}




\section{Discussion}

The results of the survey questionnaire responses supported mixed CRM for both the cockpit and cabin crews and were viewed positively by members of both types of crews. In addition, survey responses support mixed CRM as contributing to improved communication between crews, and an increase in safety was also supported.

In general, the respondents ranked CRM and mixed CRM as beneficial, although there were some differences in perceptions about what aspects were most useful. Cockpit crewmembers' responses were slightly more positive than the cabin crewmembers responses. Interestingly, more members of cockpit crews have also participated in CRM training than have cabin crewmembers, with $77 \%$ participation by cockpit crewmembers, and only $47 \%$ participation by cabin crewmembers. Of course, this may be a function of the cockpit crewmembers having had more years' experience than the cabin crews. It may also indicate something of a bias on the part of those running airlines, who view investments in cockpit crew training as more valuable and necessary than that of cabin crew training. Interestingly, there were no questions which results show greater than a ten percent differential between the cockpit and cabin crews in terms of a positive response.

Cockpit crew members felt most strongly about issues of safety, and gave the strongest responses on questions that asked about safety, as well as several that discussed effectiveness of crews. Crewmembers ranked questions about communications and communication procedures as being the most important, or potentially providing the greatest improvement in CRM training.

The survey was successful in measuring largely positive attitudes toward mixed CRM as a useful aspect of training across multiple issues within the aviation industry, perhaps most notably in areas of safety and cooperation of crew members.

\section{Conclusion}

The results of the survey indicate that a majority of both cockpit and cabin crews view CRM courses as beneficial, and in particular, rate the mixed CRM courses as high in their ability to improve areas of communication and the ability of various crewmembers to get along and perform more effectively.

One surprising aspect of the survey results is that the cockpit crews had opinions of CRM that were nearly as high as cabin crews, and which can be ranked higher on at least five different points. This is surprising since research suggests that pilots in particular are less likely to rank high in people skills, and be more appreciative of technical problem solving. It might be surmised that cockpit crews would be more hesitant to participate in CRM, or have a lower opinion of it. Although cabin crews showed slightly less positive attitudes toward CRM than cockpit crews, overall, there was a high level of similarity in positive responses to CRM between cabin and cockpit crews. It is possible that cabin crews view the cockpit crews having a greater need of communication skills, and therefore felt that the programs were of less value in mixed situations. Both cockpit and cabin crews rated briefing procedures as advantageous and important.

\section{Recommendations}

The survey results suggested that CRM is looked on favorably by a majority of employees in both cockpit and cabin crews, and would be considered a favorable aspect of job training by all employees of the airline. The airline should consider adding CRM training as a regular component of job training, such as with a yearly program, or a program required once every two years.

Research shows that mixed rather than separate CRM can help to achieve greater results in bringing together the members of the cockpit and cabin crews. However, it may be useful to also incorporate separate CRM training courses for cabin crews and cockpit crews on a less regular basis than the mixed training. There are some advantages to doing separate training, such as being able to address concerns that are specific to the one crew being addressed, and for that crew to be able to more openly discuss their particular concerns. For example, it is likely that mixed CRM would have to include more elements of commonalities between the crews, than addressing concerns that are more specific to one crew or the other.

The survey indicates that the mixed CRM sessions are considered valuable by nearly all survey participants. Both those who have participated in CRM, and those who have not, generally believe that there are benefits to be taken from having training sessions where such positive communications can take place, where concerns can be raised, and where the members of the differing crews can have exchanges outside of the formalized setting and procedures of the actual work day.

At minimum, airlines should consider implementing mixed CRM training once every two years. Scheduling such courses is, of course, difficult when the nature of the business separates people geographically, and when there is an ongoing need for employees to be performing their jobs, even around holidays and weekends. The airline will have to be aware of the difficulties of involving all employees in CRM, and will likely have to host at least three different training sessions each year in order to allow a mix of cockpit and cabin crew members to take part in mixed CRM training at least once every two years.t 
Donald S. Metscher is an assistant professor in the Department of Applied Aviation Sciences at Embry-Riddle Aeronautical University in Daytona Beach, Florida and is currently teaches in the Master of Science in Aeronautics Program. He has a B.S. in Aeronautics and Master of Business Administration in Aviation from Embry-Riddle, a Master of Science in Management from Troy State University, and a Doctor of Business Administration from Nova Southeastern University.

Marvin Smith is a professor in the Department of Applied Aviation Sciences at Embry-Riddle Aeronautical University in Daytona Beach, Florida and the Program Coordinator for the Master of Science in Aeronautics Program. He has a Masters Degree in Educational Technology from the University of Central Oklahoma and a Doctor of Educational Technology from Nova Southeastern University.

Abdullah Alghamdi completed his Master of Science Degree from Embry-Riddle Aeronautical University in Daytona Beach, Florida in December 2006. He has now returned to his job as a Pilot for Saudi Arabian Airlines. 
I. Demographics Information:

\section{Appendix A}

The following information is for research purposes only. Please, choose the best appropriate answer.

1. Age: $\frac{20-30}{2 .}$

2. Field specialization

3. Work experience: $31-40$ 41-50 $51+$

\section{SURVEY}

4. Have you ever attended mixed Crew Resource Management (CRM) training or any training on how to communicate and cooperate?

Yes No

\section{CRM Questionnaire:}

Using the scale below, please answer the following questions by writing beside each question the ranking number that best reflects your opinion.

\begin{tabular}{|ccccc|}
\hline 1 & 2 & 3 & 4 & 5 \\
Strongly Disagree & Disagree & Neutral & Agree & Strongly Agree \\
\hline
\end{tabular}

1. Flight operation "Crew Resource Management" training has the potential to increase aviation safety and teamwork effectiveness.

2. Good communication and team coordination are as important as technical proficiency for aircraft safety and operational effectiveness. correctively.

3. Language differences of crew members degrades the teamwork effort to accomplish their task effectively and

4. Younger crewmembers are likely to be more effective in the teamwork than the older crew.

5. The working relations among crew members would be improved with mix CRM Classes. Courses.

6. The important aspects of all crew members' jobs are fully acknowledged during separated cockpit/cabin crew CRM

7. A joint cockpit/cabin pre-Flight briefing would be advantageous during both normal and emergency situations.

8. Mixed CRM would help to eliminate communication breakdowns between crew members, especially in multicultural airlines. 
9. A flight crew who has received more CRM training is more likely to be more effective in teamwork than one who has received less CRM training.

10. A mixed CRM class would give you more practical ways to communicate in your daily flying.

11. Effective mixed CRM training would improve crew member behavior and motivate them to work in individual and group situations.

12. Mixed CRM training would help the crew members to work and understand crew members from other nationalities.

13. In every flight during crew change, it is important to conduct a briefing to ensure an effective and safe transition and operation.

14. Crew members should have a basic knowledge of human factors prior to entering real flight conditions in the line.

15. Mixed CRM classes would improve the trust among co-workers and improve the knowledge of each others duties. 


\section{References}

Barnes, R. B., Orlady, H. W., \& Orlady, L. M.(1996). Multi-cultural training in human factors for transport aircraft certification. Paper presented at the meeting of the International Civil Aviation Organization (ICAO), Auckland, New Zealand. Abstract retrieved February 14, 2005, from http ://s92270093.onlinehome.us/ crmdevel/resources/paper/barnes02.htm

Baron, R. (2004). The cockpit, the cabin, and social psychology. Retrieved February 14, 2005, from http://www.gofir.com/general/crm

Chute, R. D. (2002). Cabin/cockpit communication: Post 9/11. Presentation presented at the Human Factors Group of the Royal Aeronautical Society, London, England. Retrieved April 1, 2005, from http://www.raes-hfg.com/reports/10apr02Hijacking/10apr02-chute.pp\#256,1,Cabin/Cockpit Communication: Post 9/11

Chute, R. D., \& Wiener, E. L. (1995). Cockpit/cabin communication: I. A tale of two cultures. International Journal of Aviation Psychology, 5(3), 257-276.

Chute, R. D., \& Wiener, E. L. (1996). Cockpit/cabin communication: II. Shall we tell the pilots? [Electronic version]. International Journal of Aviation Psychology, 6(3),211-231.

Cooper, G. E., White, M. D., \& Lauber, J. K. (1980). Resource management on the flight deck: In Proceedings of a NASA/Industry Workshop. (NASA CP-2120). Moffett Field, CA: NASA-Ames research center.

Federal Aviation Administration. (2001). Crew resource management advisory circular (120-51D). [Electronic version]. Retrieved February 14, 2005, from http://www.faa.gov/avr/afs/acs/120-51d.pdf

Federal Aviation Administration. (2005). Title 14 Code of Federal Regulation Aeronautics and Space 121.542 (Federal Register, Vol. 46, No.5502, Rules and Regulations p. 3832). Washington, DC: Author.

Helmreich, R. L. (n.d.). Culture, threat, and error: Assessing system safety.

Retrieved February 14, 2005, from the University of Texas, Department of Psychology Web site:http:/homepage.psy.utexas.edu/homepage/group/ HelmreichLAB/ Publications/pubfiles/Pub257.pdf

Helmreich, R.L. (1992). Human factors aspects of the Air Ontario crash at Dryden, Ontario: Analysis and recommendations. In V.P. Moshansky (Commissioner), Commission of Inquiry into the Air Ontario Accident at Dryden, Ontario: Final report. Technical appendices. (pp. 319-348). Toronto, Ontario: Minister of Supply and Services, Canada.

Helmreich, R. L. (1999).Building safety on the three cultures of aviation. Retrieved March 7, 2005, from University of Texas, Department of Psychology Web site: http://homepage.psy.utexas.edu/homepage/ group/HelmreichLAB/Publications/pubfiles/pub236.pdf

Helmreich, R. L., Klinect, J. R., \& Wilhelm, J. A. (1999). Models of threat, error, and CRM in flight operations. In Proceedings of the Tenth International Symposium on Aviation Psychology. Retrieved February 14, 2005, from http://homepage.psy.utexas.eduhomepage/group/HelmreichLAB/Publications/pubfiles/Pub240.pdf

Helmreich, R. L., Merritt, A. C., \& Wilhelm, J. A. (1999). The evolution of crew resource management training in commercial aviation [Electronic version]. International Journal of Aviation Psychology, 9, 16-32. 
Helmreich, R. L., Wilhelm, J. A., Klinect, J. R., \& Merritt, A. C. (2001). Culture, error, and crew resource management. Retrieved February 14, 2005, from University of Texas, Department of Psychology Web site:http:/homepage. psy.utexas.edu/homepage/group/HelmreichLAB/Publications/pubfiles/Pub254.pdf

JAR TEL. (1998). Synthesis of Cultural Aspects and their Influences on Crew Behaviour. Final Report (SOFREAVIA, AI-97SC.2037). Paris-Issy, France.

Kern, T. (2001). Culture, environment, and CRM. New York: McGraw-Hill.

Lauber, J. K. (1984). Resource management in the cockpit. Air Line Pilot, 53, 20-23.

Lusher, D., Leary, M., \& Feaker, N. (1995). Integrating human factors into flight operations training. Proceedings of the Human Factors in Aviation Seminar and Workshops, Bahrain, 117-130.

Merritt, A. C., \& Helmreich, R. L. (1995). Culture in the cockpit: A multi-airline study of pilot attitudes and values. In R.S. Jensen \& L.A. Rakovan (eds.), Proceeding of the Eight International Symposium on Aviation Psychology, Vol. 1, 676-68.

National Transsportation Safety Board. (1979). Aircraft accident report. Mismanagement of fuel, United Airline flight 171. Douglas DC-8, N8082U, Portland, OR, December 28, 1978. (Report No. NTSB/DCA79AA005). [Electronic version]. Retrieved March 9, 2005, from http://www. ntsb. gov/ntsb/brief.asp?ev_id= 39743\&key=0

Nilsson, M., \& Roberg, J. (2003). Cockpit door safety. Retrieved February 18, 2005, from Lund University, School of Aviation Web site:http://www.flygforsk.lu.se/files/Cockpit Door Safety.pdf

Orlady, L. M., \& Orlady, H. W. (1999). Human factors in multi-crew flight operations. Aldershot, England: Ashgate.

Phillips, D. (1994, May 31). Jettisoning attitudes about flight attendants; gap with cockpit crews may lead to safety problems, aviation community realizes. The Washington Post, p. A7.

Sexton, J.B., \& Helmreich, R. L. (2000). Analyzing cockpit communication: The links between language performance, error, and workload. Human Performance in Extreme Environments, 5(1), 63-68.

Wiener, E. L., Kanki, B. G., \& Helmreich, R. L. (Eds.). (1993). Cockpit resource management. San Diego, CA: Academic Press. 
